\title{
Práticas de letramento no processo de envelhecimento
}

\author{
Literacy practicesinedderlyprocess
}

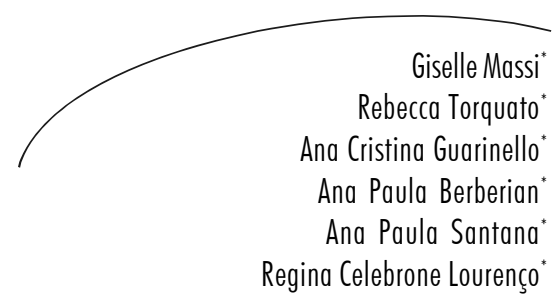

Resumo

Introdução: a interação social e o acesso à educação e à saúde dependem de processos interlocutivos que se efetivam a partir das diferentes modalidades de linguagem. Nesse sentido, as condições de leitura e de escrita, vivenciadas pelos sujeitos, assumem papel decisivo em seus processos de envelhecimento, sobretudo ao ser considerado o fato de a sociedade atual pautar-se em atividades que envolvem diferentes níveis de letramento. Objetivo: este estudo objetiva analisar as condições de letramento de um grupo de pessoas com idade mínima de 60 anos frequentadores da Unidade de Saúde da Praça Ouvidor Pardinho, em Curitiba, PR. Metodologia: Para analisar tais condições, foram aplicados um questionário e um teste de leitura contendo textos de gêneros diversos a um grupo de sujeitos idosos, frequentadores de uma Unidade Básica de Saúde, situada na cidade de Curitiba, Paraná. O questionário abrange idade, nível de escolarização, profissão, bem como práticas e situações de leitura e escrita. No teste de leitura, os sujeitos foram convocados a localizar informações explícitas nos textos e realizar inferências. Resultados: Os resultados obtidos revelam um acesso restrito da população idosa à linguagem escrita, pois apesar de os sujeitos da pesquisa afirmarem que costumam ler livros, revistas e jornais, foi possível verificar que a maioria não consegue extrair informações apresentadas em textos simples que circulam corriqueiramente no cotidiano social. Conclusão: Convém ressaltar que o cumprimento do Estatuto do Idoso brasileiro depende da implementação de políticas públicas capazes de garantir a promoção de práticas de letramento junto a pessoas em processo de envelhecimento, uma vez que sem o desenvolvimento dessas práticas não é possível contar com princípios de equidade social que possibilitem ao idoso efetivar sua cidadania.

\footnotetext{
Universidade Tuiuti do Paraná. Faculdade de Ciências Biológicas e da Saúde. Programa de PósGraduação em Distúrbios da Comunicação. Curitiba, PR, Brasil

Trabalho financiado pelo CNPq, Processo 307272/2008

Correspondência / Correspondence

Giselle Massi

E-mail: giselle.massi@utp.br
}

Palavras-chave: Relações Interpessoais. Acesso à Informação. Acesso aos Serviços de Saúde. Leitura. Compreensão. Escrita Manual. Políticas Públicas. Curitiba. Envelhecimento. Linguagem. 


\section{Abstract}

Introduction: Social interaction and access to education and health depend on intersubjective processes that become effective through different language modalities. We consider that individuals' reading and writing conditions have an important role in their ageing process. Objective: This paper aims to analyze literacy conditions of a group composed by individuals with at least 60 years old that attend a Health Unit in Praça Ouvidor Pardinho, located in Curitiba, Brazil. For that we applied a questionnaire and a reading test that hold different genres with 22 individuals. The questionnaire includes: age, school level, profession and reading and writing conditions. In the reading test, the individuals had to locate written information and realize inference. Results: The results show that these ageing population had a restrict access to written language. Conclusions: It is important to note that the fulfilment of the Brazilian Elderly Statute depends on public policies that guarantee the literacy promotion to this group of people. Without the developing of these practices, it is impossible to consider an egalitarian society that allows elderly people to be effective citizens.
Key words: Interpersonal

Relations. Access to Information. Health Services Accessibility. Reading. Comprehension. Handwriting. Public Policies. Curitiba city. Elderly. Language.

\section{INTRODUÇÃO}

Estudos e projeções têm anunciado avanços na longevidade humana, alterando o quadro demográfico mundial. É conhecido e amplamente divulgado o fato de a população mundial estar sofrendo alterações significativas no que se refere ao aumento da expectativa de vida. Para que se tenha noção da magnitude desse aumento, basta verificar o que está ocorrendo no Brasil. O tempo médio de vida da população brasileira, que no início do século XX era de 33 anos, subiu para 70,5 anos em 2000, e alcançou 71,3 anos em 2004, segundo o Instituto Brasileiro de Geografia e Estatística. ${ }^{1}$

Contudo, tendo em vista o crescimento da longevidade humana, é preciso considerar não somente o aumento na expectativa de uma vida longa, mas de uma vida com qualidade e autonomia, sem as quais o processo de envelhecimento pode trazer sérias dificuldades para a sociedade, para a família e sobretudo para o próprio sujeito que envelhece. ${ }^{2}$ Por isso, o rápido processo de crescimento na longevidade da nossa população deve ser enfatizado, especialmente quanto a suas implicações sociais e em termos de saúde pública. ${ }^{3}$

Tendo em vista tais implicações, é possível afirmar que a saúde pública brasileira está enfrentando, no século XXI, um desafio considerável: cuidar de um contingente populacional que abrange mais de 32 milhões de pessoas em processo de envelhecimento, a maioria com nível socioeconômico e educacional baixo. ${ }^{4}$ Esse desafio se traduz na viabilização de uma velhice saudável, a partir da qual as pessoas sejam capazes de gerir suas próprias vidas, determinando quando, onde e como desenvolver atividades de lazer, convívio social e trabalho.

A busca pela implementação de políticas públicas voltadas a esse segmento da sociedade brasileira vem resultando no desenvolvimento de programas vinculados ao lazer, à cultura e à educação, além daqueles relacionados à saúde, ao trabalho e à assistência dessa população. $\mathrm{Na}$ tentativa de dar conta de um envelhecimento ativo, vivenciado a partir de processos educativos e de atitudes pautadas em princípios de equidade social, foram recentemente desenvolvidos, no Brasil, o Estatuto do Idoso ${ }^{5}$ a Política Nacional do Idoso (PNI). ${ }^{6}$

Mais especificamente no ano de 2004, foi sancionada a Lei Federal $n^{\circ} 10.741$, de acordo com o Diário Oficial da União de 03 de outubro de 2004, que criou o Estatuto do Idoso brasileiro, com o objetivo de regular os direitos assegurados às pessoas com idade igual ou superior a 60 anos. 
A criação desse Estatuto constitui um marco histórico constitucional quanto ao envolvimento das esferas administrativas e governamentais, as quais foram responsabilizadas pelas ações que devem ser garantidas a toda população idosa do país. Segundo anuncia o Estatuto, é obrigação da comunidade, da sociedade e do Poder Público assegurar ao idoso, com absoluta prioridade, a efetivação do direito à vida, à saúde, à educação, ao esporte, ao lazer, ao trabalho, à cidadania, à liberdade, à dignidade, ao respeito e à convivência familiar e comunitária.

Segundo Orso, ${ }^{7}$ enfocar os direitos assegurados às pessoas com 60 anos ou mais significa ressaltar questões referentes à saúde e à educação, uma vez que essas duas áreas são fundamentais para o desenvolvimento humano, devendo ser concebidas de maneira articulada, pois ambas abrangem todos os demais aspectos asseverados aos idosos, tais como acesso ao trabalho, ao lazer, à liberdade, à dignidade, ao respeito e à convivência. Da mesma forma, para Queiroz et al, ${ }^{8}$ um envelhecimento ativo e saudável depende do desenvolvimento de programas capazes de abranger aspectos relacionados à saúde, à sociabilidade e à educação. Afinal, os objetivos que fundamentam ações de saúde voltadas a pessoas idosas são os de mantê-las independentes física e mentalmente na comunidade e no seio familiar. Para tanto, proporcionar oportunidades educacionais ao idoso é um empreendimento que deve ser considerado na atenção primária à saúde pelas Unidades Básicas de Saúde em todo território nacional. ${ }^{9}$

Assim, assumindo que a interação social e que o acesso à educação e à saúde dependem, inevitavelmente, de processos interlocutivos que se efetivam no espaço de produção da linguagem, este trabalho objetiva enfocar o papel que as atividades de leitura e de escrita podem assumir no processo de envelhecimento. A perspectiva discursiva é tomada como referencial, neste estudo, uma vez que a linguagem - como atividade simbólica, como efeito de sentido - promove a (re)organização contínua da história de cada sujeito. O que é dito e escrito resulta de processos de significação e de ressignificação que marcam a subjetividade dos sujeitos, tornando-os autores da vida singular que está em constituição permanente.

De acordo com Franchi, ${ }^{10}$ é na e pela linguagem oral e escrita que os sujeitos se constituem no decorrer de toda a vida. Por isso, as trocas simbólicas estabelecidas em atividades linguístico-discursivas de leitura e de escrita devem ser tomadas como eventos privilegiados de interlocução para sujeitos que estão envelhecendo. Uma vez que a linguagem não é um mero objeto pronto e estabilizado, tampouco a representação do pensamento individual, mas uma prática que se dá nas relações sociais e, portanto, intersubjetivas, é possível entender que a produção, a organização e a interpretação de dados linguístico-discursivos produzidos pelos sujeitos que usam a linguagem devem ser alinhadas na perspectiva do texto.

A perspectiva discursiva parte de uma concepção de linguagem dialógica e social, pois é o signo verbal produzido nas interações dialógicas que constitui cada homem. Para fundamentar este estudo, a teoria de Bakhtin ${ }^{11}$ é assumida, a partir da qual a realidade psíquica é de natureza semiótica, uma vez que não é possível analisar essa realidade e compreendê-la senão como um signo. Tendo em vista que o signo é um elemento da realidade externa que compõe o universo da interação verbal, a organização da atividade mental não se dá no interior do sujeito mediante características que lhe são inerentes, mas no próprio fluxo das relações dialógicas que se explicitam textualmente por meio de falantes e de ouvintes, de escritores e de leitores.

Portanto, o presente trabalho de pesquisa rejeita uma visão que privilegia unicamente os processos internos dos sujeitos em processo de envelhecimento e entende tais sujeitos a partir da permanente troca dialética que estabelecem com o mundo social em que estão inseridos. Esse entendimento permite focalizar a constituição da subjetividade em função da interação verbal, a qual se organiza a partir de um conjunto de valores que refletem e refratam diferentes visões de mundo. Portanto, a leitura e a produção textual 
de um sujeito em processo de envelhecimento, vinculadas a um emaranhado de valores que permeiam suas relações sociais e interacionais, são atividades que estão diretamente relacionadas com a maneira como esse sujeito se afirma, se organiza e se insere no mundo.

O uso da linguagem pressupõe invariavelmente a possibilidade de significar. Nesse sentido, a concepção de que o discurso liberta o sujeito de uma condição de mero organismo abstrato, ou seja, de sua condição de objeto, ressalta a necessidade de situar o sujeito que envelhece numa dimensão histórica e social. Questões referentes ao uso da linguagem oral e escrita anunciam uma perspectiva que não se resume ao aspecto orgânico e fisiológico do sujeito que envelhece, mas compreende o próprio universo de constituição permanente da consciência desse sujeito marcada socialmente pela e na intersubjetividade.

Dessa forma, torna-se imprescindível a promoção de práticas discursivas de letramento junto a sujeitos que estão em processo de envelhecimento, para que cada um exerça plenamente sua cidadania, seu papel social, fazendo valer seu direito a uma vida saudável $\mathrm{e}$ autônoma, na medida em que participa de maneira ativa e crítica de ações mediadas pela escrita. Letramento é o exercício efetivo e competente da tecnologia da escrita, ou seja, é o estado que assume aquele que sabe ler e escrever para cumprir objetivos diversos: informar e informar-se, interagir com o outro, fazer uma declaração, entender uma receita médica, contar uma história, ampliar conhecimentos, divertir, fazer valer os seus direitos, reconhecer os seus deveres, entre outros. ${ }^{12}$

Os usos e domínio da leitura e da escrita relacionados a diferentes contextos sociais vêm sendo reconhecidos como letramento. Este termo, segundo Soares, ${ }^{12}$ refere-se à condição de quem sabe ler e escrever, isto é, refere-se ao estado de quem responde adequadamente às intensas demandas sociais pelo uso amplo e diversificado da leitura e da escrita. Portanto, diferentemente da alfabetização - relacionada ao domínio da tecnologia da escrita e que depende do estabelecimento das relações fonemas/grafemas; do entendimento de que o ato de escrever se organiza da esquerda para direita e de cima para baixo; da possibilidade de uso de materiais próprios para a escrita, tais como lápis, borracha e computador -, o letramento é um processo contínuo que insere cada sujeito nas tramas sociais da sua comunidade.

Como são variadas as práticas sociais que demandam o uso da leitura e da escrita, também são variadas as habilidades, conhecimentos e atitudes necessárias para o exercício dessas práticas. Por isso, avaliar e medir o letramento não são tarefas simples, uma vez que o letramento é um fenômeno complexo que não se deixa mensurar de maneira fácil e direta. De qualquer forma, definir formas de avaliação e medição de letramento é indispensável para que sejam verificados os índices de progresso de uma sociedade e, nessa direção, determinados a organização e o planejamento de políticas públicas de bem estar social. ${ }^{13}$

A pesquisa realizada pelo Instituto Brasileiro de Opinião Pública e Estatística (IBOPE),${ }^{14} \mathrm{com}$ duas mil pessoas representativas da população brasileira com idade entre 15 e 64 anos, residentes em zonas rurais e urbanas em todas as regiões brasileiras, é um exemplo de medição de letramento no Brasil. Segundo Ribeiro et al, ${ }^{15} \mathrm{tal}$ pesquisa se deu a partir de dois instrumentos: um teste de leitura e um questionário para obter informações acerca do nível de escolaridade das pessoas envolvidas na pesquisa, os usos que fazem da leitura e da escrita em contextos diversos, bem como a opinião que têm sobre suas próprias possibilidades e disposição para ler e escrever. Em função desse estudo, foi criado o Indicador Nacional de Alfabetismo Funcional (INAF), cujos resultados denunciam que o Brasil é uma nação na qual a cultura letrada está amplamente disseminada, mas de maneira desigual e insatisfatória.

Dentre a população pesquisada pelo INAF, além de $9 \%$ de analfabetos, $31 \%$ alcançaram um nível rudimentar de letramento, localizando informações explícitas em textos muito curtos; $34 \%$ demonstraram 
estar em um nível médio de letramento, reconhecendo informações em textos curtos e médios, mesmo que tal informação não estivesse apresentada de maneira literal; e apenas $26 \%$ da população atingiram um nível pleno de letramento, lendo textos mais longos, podendo orientar-se por subtítulos, relacionando partes do texto e realizando inferências. ${ }^{14}$ Portanto, embora a maioria da população brasileira se apresente alfabetizada, está longe de atingir um nível pleno de letramento, ou seja, está longe de conseguir fazer uso significativo da leitura e da escrita em diversas atividades sociais, ficando à margem da sociedade grafocêntrica atual.

Ressalta-se, ainda, que a população acima de 60 anos tem sido geralmente negligenciada nesse tipo de estudo. Por isso, com base na pesquisa desenvolvida pelo IBOPE ${ }^{14}$ no ano de 2001, pretende-se analisar as condições de letramento de um grupo de pessoas com idade mínima de 60 anos frequentadores da Unidade de Saúde da Praça Ouvidor Pardinho, na cidade de Curitiba. Tal análise é indispensável para a organização de ações envolvidas com a integração social dessa população e, nessa direção, com o binômio saúde-educação.

\section{METODOLOGIA}

A pesquisa, aprovada pelo Comitê de Ética da Universidade Tuiuti do Paraná sob o protocolo de número 102/2008, foi realizada na Unidade de Saúde da Praça Ouvidor Pardinho, no bairro Rebouças da cidade de Curitiba, uma vez que essa unidade volta sua atenção especificamente ao atendimento de pessoas idosas.

Participaram da pesquisa 22 sujeitos com idade superior a 60 anos, sendo que todos eles assinaram um Termo de Consentimento Livre e Esclarecido, o qual explicava os passos da pesquisa, bem como seu objetivo e justificativa. Esses sujeitos foram selecionados durante os anos de 2006 e 2007 a partir da própria busca em participar de uma Oficina de Linguagem, voltada ao desenvolvimento de atividades de leitura e escrita.

Quanto à Oficina da Linguagem, cabe esclarecer que a mesma é oferecida anualmente a todos os usuários da Unidade de Saúde da Praça Ouvidor Pardinho, promovida em convênio com a Universidade Tuiuti do Paraná, e aqueles idosos que têm interesse se inscrevem e participam das atividades durante um ano letivo. Portanto, os participantes da pesquisa foram selecionados, dentre todos os usuários da referida Unidade de Saúde, a partir do interesse em desenvolver atividades de letramento. Cabe esclarecer que foram excluídos do estudo sujeitos idosos com doenças cerebrais degenerativas e com alterações neurológicas relacionadas à linguagem.

Para analisar as condições de letramento desses 22 sujeitos - 10 inscritos no ano de 2006 e 12 no ano de 2007 -, foram utilizados dois instrumentos, elaborados e adaptados em função do estudo realizado pelo IBOPE, ${ }^{15}$ já citado anteriormente: um questionário e um teste de leitura contendo diferentes textos de gêneros diversos: um cartaz, um bilhete, uma notícia e uma fábula. Esses instrumentos foram usados logo que os sujeitos se inscreveram para participar das atividades. Portanto, eles responderam ao questionário e ao teste de leitura antes de se envolverem nas atividades de leitura e escrita propostas, durante os anos de 2006 e 2007 , nas oficinas.

O questionário é composto por perguntas abertas, abrangendo questões relacionadas a idade, nível de escolarização, profissão, bem como práticas e situações de leitura e escrita. A partir desse questionário, foram coletadas informações sobre as práticas de leitura e de escrita presentes na vida dos sujeitos da pesquisa e também a noção que eles têm sobre suas próprias possibilidades e dificuldades para ler e escrever.

No teste de leitura, algumas questões propostas exigiram dos sujeitos da pesquisa a possibilidade de localizar informações em textos breves, com estruturas simples, temáticas e vocabulário familiares, enquanto outras, em textos mais longos, com estruturas mais complexas, exigiram maior necessidade da produção de inferências.

As respostas fornecidas ao questionário e ao teste foram analisadas por meio do software de 
análise estatística Sphinx, o qual permitiu caracterizar as condições de letramento dos sujeitos participantes, bem como suas práticas de leitura e de escrita, conforme os resultados apresentados na sequência.

\section{RESULTADOS}

Com relação à análise das respostas dadas aos questionários, é possível afirmar, no que se refere à caracterização geral da amostra pesquisada, que $73 \%$ dos sujeitos participantes do estudo são do sexo feminino e $27 \%$ do sexo masculino. Além disso, $63 \%$ dos entrevistados apresentam entre 60 e 70 anos de idade, $14 \%$ têm idade que varia entre 71 e 75 anos e $23 \%$ apresentam idade superior a 75 anos. No que se refere ao grau de escolaridade dos sujeitos da pesquisa, $40 \%$ afirmam ter grau de escolaridade compatível com o ensino fundamental, sendo que deste total $14 \%$ não chegaram a concluir a oitava série. Além disso, $18 \%$ da amostra concluíram o ensino médio, $23 \%$ concluíram um curso de graduação e $5 \%$ fizeram pós-graduação, conforme apresentado na figura 1.

\footnotetext{
- Ensino Fundamental

Incompleto $14 \%$

Ensino Fundamental Completo $27 \%$

- Ensino Médio Incompleto 4\%

- Ensino Médio Completo $18 \%$

- Graduação Incompleta $9 \%$

Graduação Completa 23\%

— Pós-Graduação 5\%
}

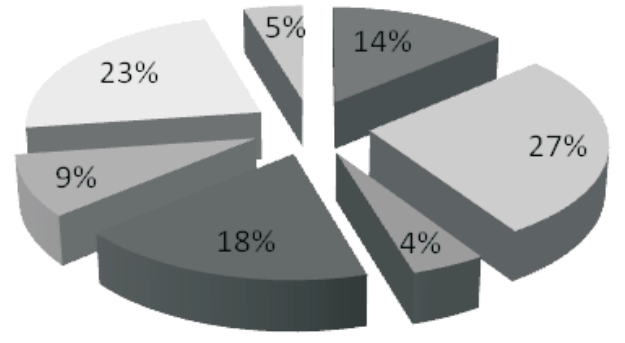

Figura 1: Grau de Escolaridade - Fonte: pesquisa de campo.

No que se refere especificamente a questões vinculadas à leitura, 91\% dos sujeitos da pesquisa relatam ter o hábito de ler. Dentre os hábitos de leitura citados, a figura 2 revela que $27 \%$ referem ler revistas, $25 \%$ afirmam ler livros, $23 \%$ relatam que leem livros religiosos, $14 \%$ mencionam que leem jornais, $9 \%$ afirmam ler outros materiais escritos, mas não especificaram quais seriam esses materiais, e $2 \%$ dos sujeitos não responderam a essa questão. 


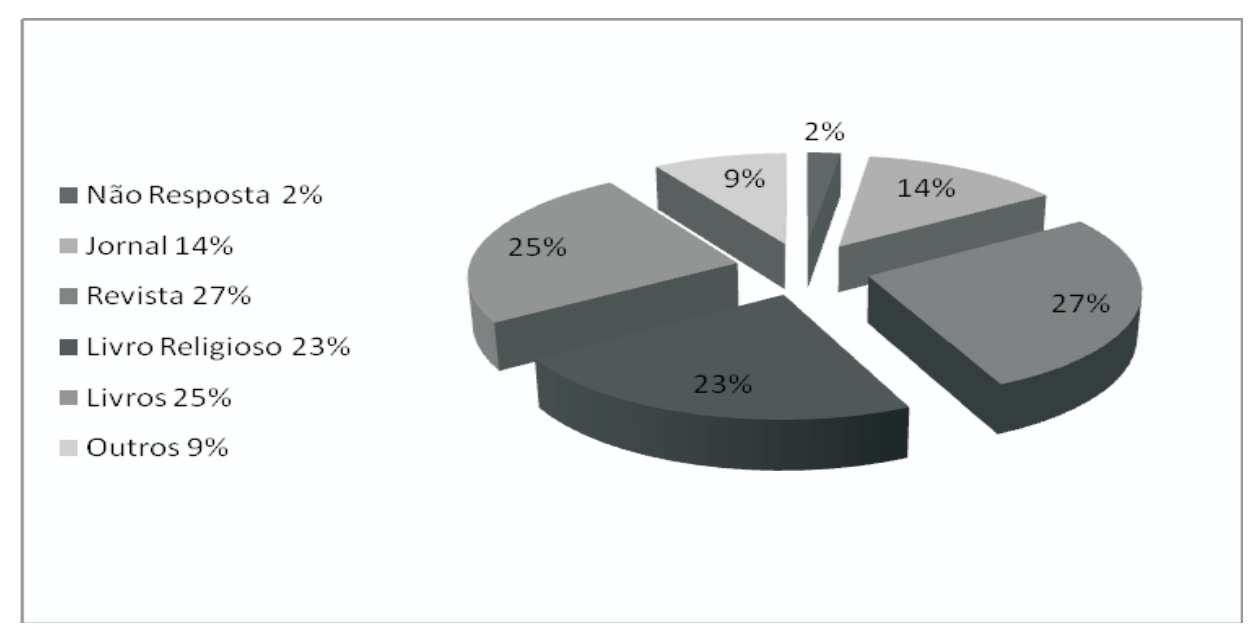

Figura 2: Hábitos de leitura - Fonte: pesquisa de campo.

Mais da metade da amostra, $52 \%$ dos sujeitos da pesquisa, mencionam que costumam ler em casa, $15 \%$ afirmam ler na igreja, $11 \%$ relatam fazer leituras em consultórios, $7 \%$ responderam que fazem leituras em outros locais, mas não especificaram quais seriam esses locais, $7 \%$ não responderam a essa questão, $4 \%$ responderam que fazem leituras na escola e $4 \%$ referem ler no trabalho. Chama atenção o fato de
$46 \%$ dos idosos afirmarem ter dificuldades com a leitura. Dentre tais dificuldades, $23 \%$ deles apontam que têm problemas com a gramática da língua, $32 \%$ denunciam cansaço e falta de concentração para leitura, $36 \%$ relatam ter dificuldade para compreender o que estão lendo e $9 \%$ afirmam ter visão comprometida, de acordo com a figura 3, apresentada a seguir.

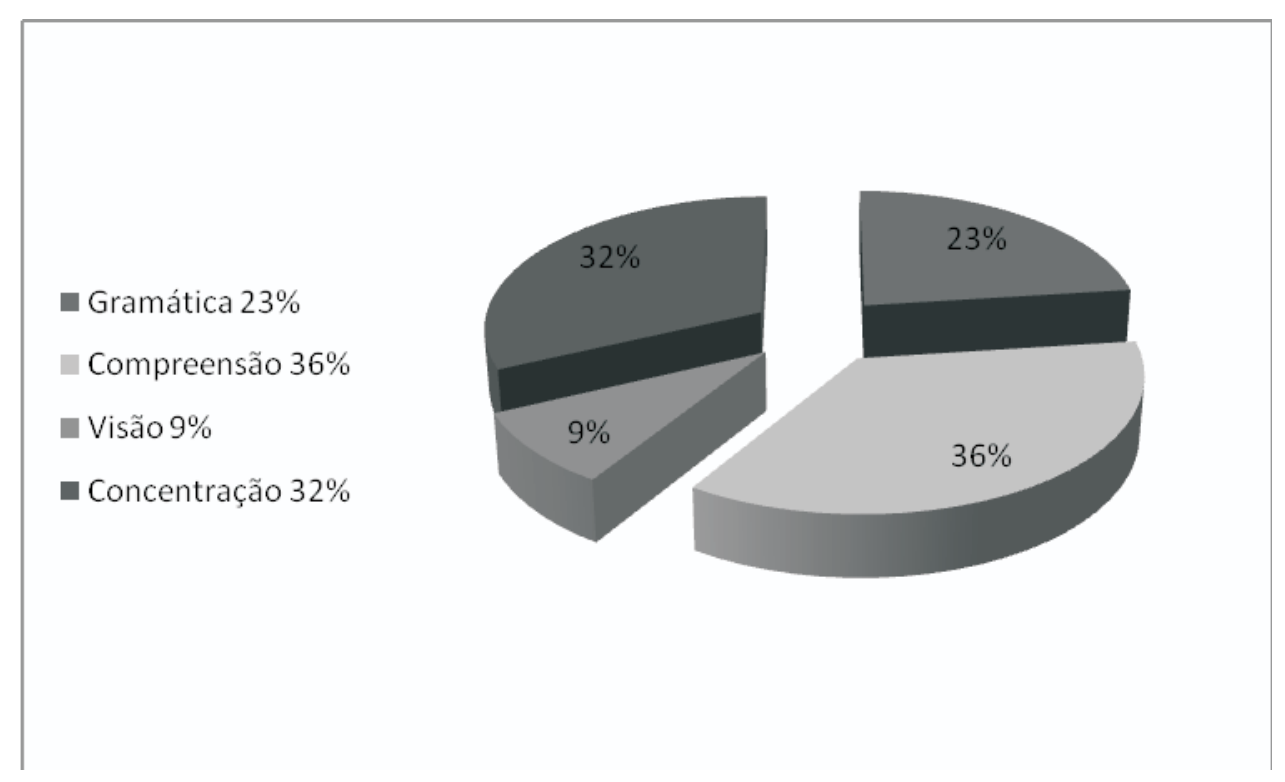

Figura 3: Dificuldades com a leitura - Fonte: pesquisa de campo. 
No que tange às práticas com a escrita, apenas $27 \%$ dos idosos referem ter o hábito de escrever diariamente. Na figura 4, é possível observar que $28 \%$ afirmam escrever receitas culinárias, $25 \%$ escrevem bilhetes, $25 \%$ referem ter o hábito de escrever outros materiais, sem especificar quais seriam esses materiais, $13 \%$ escrevem cartas e $9 \%$ referem fazer uso corriqueiro da escrita para elaborar listas de compras.
Bilhete $25 \%$

Receita $28 \%$

- Carta $13 \%$

- Lista de Compras $9 \%$

Outros $25 \%$
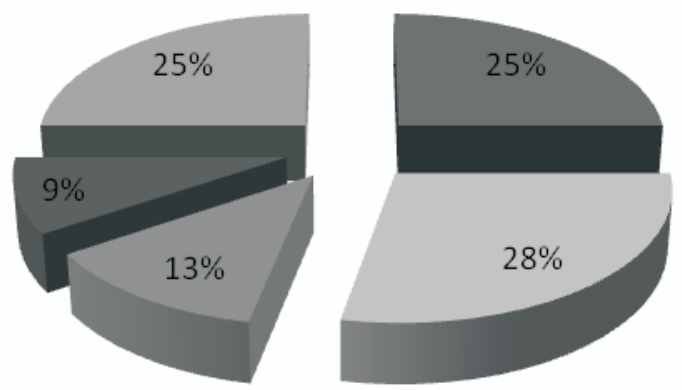

Figura 4: Hábitos de escrita - Fonte: pesquisa de campo.

Além disso, $41 \%$ da amostra afirmam apresentar alguma dificuldade em relação à escrita, sendo que desse total, 54\% relatam ter problemas vinculados a questões ortográficas,
$38 \%$ mencionam não conseguir expressar o que desejam por meio da escrita e $8 \%$ afirmam ter alguma dificuldade motora para escrever, conforme a figura 5 .
- Ortográficas 54\%

— Expressão 38\%

- Motoras $8 \%$

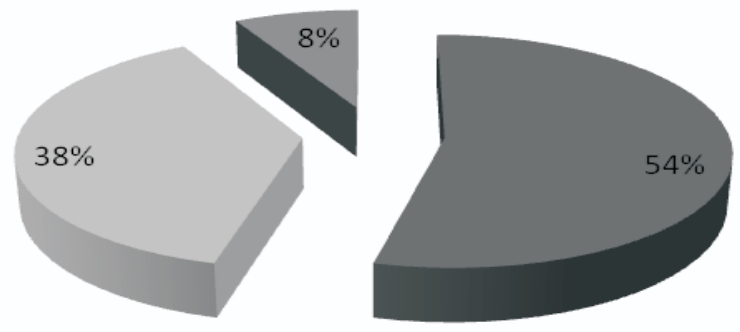

Figura 5: Dificuldades com a escrita - Fonte: pesquisa de campo. 
No que se refere ao teste de leitura envolvendo diferentes gêneros textuais, o primeiro texto usado foi um cartaz, apresentado na sequência.

Você que tem carteira de trabalho assinada há mais de dois anos

$$
\text { CERTIFIQUE-SE DE SEUS DIREITOS!!!! }
$$

Dirija-se a uma agência da Caixa Econômica Federal, até 30 de outubro, e verifique seu PIS / PASEP

Após ler tal texto, para verificar a habilidade dos idosos em identificar uma informação explícita num cartaz publicitário, os sujeitos tinham que responder a duas perguntas. A primeira, que questionava "para quem o cartaz foi escrito?", foi respondida com $82 \%$ de erros, sendo que a resposta estava explicitamente apresentada no referido cartaz. $\mathrm{Na}$ segunda pergunta, que indagava "até quando os trabalhadores devem dirigir-se à Caixa Econômica Federal?”, 18\% dos sujeitos responderam inadequadamente. A exemplo da primeira questão, a resposta também estava explicitada no texto.

No segundo texto, os sujeitos tinham que responder a duas perguntas após a leitura da notícia apresentada a seguir.

\section{Vazamento provoca deslizamento na Babia}

\section{A Marinha e a Empresa Baiana de Água e Saneamento (Embasa) vêm trocando acusações sobre a responsabilidade do acidente.}

Salvador. O Departamento de Polícia Técnica da Babia concluiu que foi mesmo o vazamento de um cano que provocon o deslizamento de terra no bairro da Barra, na semana passada. "O acidente ocorreu por causa do vazamento no terreno da Marinha", disse o delegado Ruy Pereira da Pa₹, da $1^{a}$ Delegacia, responsável pelo caso. Ele anuncion que a próxima etapa da investigação é saber se a ligação de água era clandestina. "Se isso for comprovado, vamos buscar quem faça essa ligação". O deslizamento atingiu três edifícios da Rua Marquês de Caravelas, matando a engenheira Maria Janete Gonzaga de Araíjo, a médica Lúcia Penteado e sua filha Alice, de 1 ano.

A marinha e a Empresa Baiana de água e Saneamento (Embasa) vêm trocando acusaçoes. Aparentemente, a ligação do cano de água na rede pública foi feita pela Marinha para abastecer apartamentos de oficiais no Morro do Gavaza. No entanto, o $2^{\circ}$ Distrito Naval entende que o reparo de vazamento é de responsabilidade da Embasa. A estatal divulgou nota afirmando que a ligação estava localizada no terreno da Marinha e era clandestina.

Na primeira pergunta, "Quantaspessoas morreram por causa do deslizamento?", $4 \%$ dos sujeitos responderam adequadamente e outros $14 \%$ não responderam. Na segunda pergunta, "Segundo a Embasa, por que a Marinha seria responsávelpelo acidente?", $50 \%$ dos sujeitos responderam equivocadamente e $23 \%$ deles não responderam. Cabe ressaltar que a elaboração da resposta adequada a essa pergunta envolvia a elaboração de uma inferência por parte dos leitores, ou seja, envolvia entendimento a respeito do contexto da notícia, que não estava explícito no texto. 
Após a leitura do gênero bilhete, apresentado na sequência, os sujeitos da pesquisa responderam a duas perguntas.

Marilia:

Ontem eu fui até sua casa e você não estava. Gostaria de convidar-lhe para uma festinha surpresa. É que minha irmã vai completar 17 anos e a turma vai se reunir sábado, no salão do prédio onde eu moro. Conto com sua presença e habitual alegria!

\section{Giovana}

$\mathrm{Na}$ primeira pergunta, que questionava o motivo de Giovana ter escrito para Marília, 41\% dos sujeitos responderam inadequadamente e outros $41 \%$ não responderam. Em resposta à segunda questão, que perguntava “ $A$ irmã de quem estava fazendo aniversário?", houve $36 \%$ de respostas incorretas e $14 \%$ de respostas em branco.
Com relação à fábula apresentada a seguir, também foram verificadas várias respostas deixadas em branco ou elaboradas de forma inadequada.

\section{O Burro que vestiu a pele de um leão}

Um burro encontrou a pele de um leão que um caçador tinha deixado na floresta. Na mesma bora o burro vestiu a pele e inventou a brincadeira de se esconder numa moita e pular fora sempre que passasse algum animal. Todos fugiam correndo assim que o burro aparecia. O burro estava gostando tanto de ver a bicharada fugir dele correndo que começou a se sentir o rei leão em pessoa e não conseguiu segurar um belo zurro de satisfação. Ouvindo aquilo, uma raposa, que ia fugindo com os outros, parou, virou-se e se aproximou do burro rindo - Se você tivesse ficado quieto, talvez, eu também tivesse levado um susto. Mas aquele zurro bobo estragou a brincadeira.

Nessa fábula, os idosos foram convocados a responder a duas perguntas. Para a primeira, "Por que toda bicharada saía correndo assim que o burro aparecia?”, $27 \%$ dos sujeitos responderam de forma inadequada e $14 \%$ não responderam. Já em resposta à pergunta sobre o que levou o burro a soltar um zurro de satisfação, $23 \%$ dos sujeitos responderam errado e outros $14 \%$ deixaram a questão sem resposta.

\section{DISCUSSÃO}

Com relação à caracterização geral da amostra pesquisada, conforme anunciado nos resultados, é possível afirmar que o percentual de $73 \%$ de sujeitos do sexo feminino aponta para a prevalência de mulheres nesta pesquisa, o que está em concordância com o Instituto Brasileiro de Geografia e Estatística (IBGE) ${ }^{16}$ Conforme o referido Instituto, a população idosa brasileira se constitui predominantemente por mulheres. Além disso, convém comentar que os sujeitos $\mathrm{da}$ pesquisa eram usuários da Unidade de Saúde da Praça Ouvidor Pardinho e participavam de várias atividades, como ginástica, dança, oficinas da memória e da linguagem, as quais tendem a ser mais procuradas por mulheres. ${ }^{17}$ 
No que se refere ao grau de escolaridade dos entrevistados, é possível afirmar que a maior parte deles $(40 \%)$ refere ter grau de escolaridade compatível com o ensino fundamental, sendo que desse total, 14\% não chegaram a concluir a oitava série. Esses resultados se apresentam em conformidade com pesquisa realizada pela Fundação Perseu Abramo, ${ }^{18}$ a qual indica que grande parte da população idosa, no Brasil, não ultrapassou a oitava série do Ensino Fundamental. Segundo Camarano et al., ${ }^{19}$ a escolaridade de idosos brasileiros, considerada a partir do número de anos de estudo formal, é expressivamente baixa. Contudo, de acordo com os mesmos autores, tal situação vem sofrendo gradativa modificação, uma vez que a escolarização da população mais jovem aponta avanços significativos na educação formal dos futuros idosos brasileiros num curto período de tempo.

Outra questão a ser considerada, tendo em vista que a maioria da amostra pesquisada é constituída por pessoas de sexo feminino, é a educação formal das mulheres nas décadas passadas. Na década de 1930, as mulheres brasileiras, embora partilhando de uma sociedade machista e patriarcal, já haviam conquistado o direito à participação no ensino superior e na atividade política nacional. Porém, somente com o avanço econômico ocorrido nos anos 1960 e 1970, no Brasil, é que se intensificou a participação feminina no processo produtivo. Assim, na medida em que a mulher foi absorvida pelo mercado de trabalho, ela foi se vendo obrigada a buscar formação acadêmica superior. ${ }^{20}$

No que se refere à posição dos sujeitos da pesquisa sobre suas possibilidades e dificuldades para ler e escrever, chama atenção o número de entrevistados que afirma apresentar dificuldades para desenvolver atividades de leitura e de escrita. Os dados apontam que $46 \%$ da amostra assumem ter dificuldades com a leitura e $41 \%$ assumem ter dificuldades com a escrita. Entretanto, cabe ressaltar que, dentre as dificuldades relatadas, as menos expressivas estão relacionadas com aspectos orgânicos que poderiam estar associados a um declínio biológico próprio do envelhecimento humano, tais como baixa acuidade visual e alterações motoras.
Somente $8 \%$ da amostra relacionam suas dificuldades para escrever a aspectos motores, contra $92 \%$ que vinculam suas dificuldades a questões ortográficas e a problemas para se expressar por meio da escrita. Provavelmente, esses $92 \%$ apresentaram dificuldades para escrever que se estenderam por toda a vida e nada têm de relação com o processo de envelhecimento biológico.

Da mesma forma, somente $9 \%$ da amostra associam suas dificuldades para ler à visão comprometida, enquanto a maior parte dos entrevistados, $91 \%$ dos que assumem tais dificuldades, relaciona as mesmas a aspectos gramaticais e problemas para entender o que leem. Portanto, tanto as dificuldades de leitura como as de escrita relatadas por esses sujeitos devem estar associadas ao processo de letramento deles. $\mathrm{Ou}$ seja, suas dificuldades devem estar relacionadas às suas possibilidades de fazer uso da leitura e da escrita de acordo com as demandas sociais vigentes. Convém ressaltar que os estudos de Ribeiro ${ }^{14}$ apontam que apenas $26 \%$ da população brasileira, entre 15 e 64 anos de idade, atingiram, no ano de 2001, um nível pleno de letramento. Embora 91\% da população nacional se apresentem alfabetizados, estão longe de poder fazer uso significativo da leitura e da escrita em diversas atividades sociais.

Cabe destacar que a pesquisa de Ribeiro ${ }^{14}$ abrange a população brasileira de diversas idades. Por isso, há de se compreender que as dificuldades relativas ao letramento da população idosa podem se apresentar de forma mais contundente, uma vez que tal população, quando jovem, não vivia numa sociedade centrada na escrita e, portanto, não se constituiu em função de práticas de letramento.

De acordo com Soares, ${ }^{12}$ medidas censitárias, no Brasil de 1940, voltavam-se para avaliação de índices de alfabetização da população e não de letramento. Tanto que o Censo de 1940 considerava alfabetizada a pessoa que soubesse assinar seu próprio nome, refletindo uma sociedade que não voltava sua atenção para a linguagem escrita. Quanto a essa questão, vale ressaltar que o processo educacional formal pelo qual os sujeitos idosos passaram é diferente do processo educacional atual. 
Afinal, somente a partir da década de 1990 é que a educação brasileira passou a focar sua atenção num trabalho pautado no letramento em função de gêneros textuais diversos. ${ }^{21}$ Portanto, é provável que as pessoas com mais idade não tenham contado com um acesso a diferentes gêneros textuais durante os anos que frequentaram a escola.

No que se refere ao teste de leitura aplicado junto aos idosos participantes do estudo, chama a atenção o fato de $82 \%$ não conseguirem identificar uma informação explícita em um cartaz. Ou seja, em um material escrito, frequentemente, disposto em espaços sociais diversos para ser lido e compreendido pela população.

Além disso, apenas $18 \%$ dos sujeitos se mostraram capazes de retirar uma informação a partir da organização de um bilhete. Essa era uma questão que envolvia habilidade, por parte do leitor, de encontrar uma informação explícita no texto a partir da organização formal de um bilhete. No que se refere ao gênero notícia, $73 \%$ da amostra não conseguiram fazer inferência em um nível mais complexo para identificar uma informação implícita no texto. Quanto ao gênero fábula, houve $41 \%$ de erros e falta de respostas para as duas perguntas realizadas, sendo que ambas exigiam do leitor apenas a possibilidade de localizar informações que apareciam explicitamente no texto em questão.

Cabe comentar que esses diferentes textos um cartaz, um bilhete, uma notícia e uma fábula - constituem gêneros textuais absolutamente presentes nos diversos espaços sociais. Entretanto, os sujeitos idosos da pesquisa não demonstram ter condições de extrair o conteúdo básico do que leem. Ressalte-se também o fato de que muitas questões não foram sequer respondidas, permitindo inferir que esses sujeitos podem não ter conseguido entender o que estava escrito nas questões para respondê-las. Assim, apesar de 91\% afirmarem ter o hábito de ler diversos materiais jornais, revistas livros -, em uma avaliação simples de leitura é possível perceber que grande parte não consegue extrair informações explicitamente apresentadas em textos simples que circulam corriqueiramente no cotidiano social vigente.
Para finalizar esta discussão, convém explicitar que, embora os resultados da pesquisa estejam vinculados a uma amostra composta por 22 sujeitos, eles se apresentam compatíveis com o estudo realizado pela Fundação Perseu Abramo (2007), sobre o nível de letramento da população idosa no Brasil. Esse estudo indica que $49 \%$ dessa população são considerados analfabetos funcionais, sendo que deste total, $23 \%$ declaram não saber ler e escrever, $4 \%$ afirmam só saber ler e escrever o próprio nome e $22 \%$ consideram a leitura e a escrita atividades penosas, seja por deficiência no aprendizado, problemas de saúde, ou por ambos os motivos.

Portanto, parece ficar evidente a necessidade do desenvolvimento de pesquisas e ações voltadas a atividades de letramento junto à população de pessoas que estão em processo de envelhecimento, para que a mesma não permaneça à margem $\mathrm{da}$ sociedade atual.

\section{CONCLUSÃO}

Os resultados obtidos nesta pesquisa revelam que a população idosa tem acesso restrito a práticas significativas com a linguagem escrita, pois apesar de afirmarem que costumam ler livros, revistas e jornais, foi possível verificar que a maioria não consegue extrair informações apresentadas em textos simples que circulam socialmente. Esse fato aponta para a urgência da implementação de políticas públicas capazes de garantir a promoção de práticas de letramento junto a pessoas em processo de envelhecimento.

Afinal, se o Estatuto do Idoso Brasileiro ${ }^{5}$ afirma que é obrigação do Poder Público assegurar ao idoso, com absoluta prioridade, a efetivação do direito à vida, à saúde, à educação, à dignidade, ao trabalho, à cidadania e à liberdade, cabe ao mesmo viabilizar a promoção de atividades que priorizem o desenvolvimento de práticas de letramento junto a pessoas idosas. Sem o desenvolvimento dessas práticas, não é possível contar com princípios de equidade social que possibilitem ao idoso efetivar seus direitos básicos de cidadão. 
A partir dessas considerações, é preciso apontar para a necessidade de ampliar estudos sobre a temática desenvolvida neste estudo, levando em conta outras variáveis, tais como: diferenças entre gênero, diversidades entre grupos de idosos de níveis culturais e socioeconômicos distintos, análise da produção de textos de pessoas idosas. Se por um lado a presente pesquisa avançou no entendimento das condições de letramento dessas pessoas, por outro, ela evidenciou a necessidade de continuidade desta discussão, para ampliar a compreensão sobre práticas de leitura e de escrita no contexto da gerontologia.

\section{REFERÊNCIAS}

1. Instituto Brasileiro de Geografia e Estatística (IBGE). Estudos e pesquisas - informação demografia e socioeconômica. Rio de Janeiro; 2004.

2. Jardim SEG. Aspectos socioeconômicos do envelhecimento. In: Papaléo Netto M, organizador.Tratado de Gerontologia. São Paulo: Atheneu; 2007. p. 185-98.

3. Coelho Filho JM, Ramos LR. Epidemiologia do envelhecimento no nordeste do Brasil: resultados de inquérito domiciliar. Rev Saúde Pública 1999; 33 (5): 87-98.

4. Ramos LR. Fatores determinantes do envelhecimento saudável em idosos residentes em centro urbano. Projeto Epidoso, São Paulo. Cad Saúde Pública 2003; 19(3): 76-89.

5. Brasil. Lei no 10.741 - de 01 de outubro de 2003 [acesso 2006 Nov 11] Disponível em: http:// www.planalto.gov.br/civil/leis/2003/1. 10.741.

6. Brasil. Política Nacional do Idoso. Decreto ${ }^{\circ}$ 1948, de 03 de julho de 1996. [acesso 2006 nov 11] Disponível em: http://www.planalto.gov.br/ legislação/decreto/D 1948. htm.

7. Orso JP. Educação e saúde: interdisciplinaridade como desafio. Revista Online Biblioteca Professor Joel Martins 2000; 2 (1): 32-44.

8. Queiroz ZPV, Papaléo Netto M. Envelhecimento bem-sucedido: aspectos biológicos, psicológicos e socioculturais. Importância da sociabilidade e da educação. In: Papaléo Netto M, organizador. Tratado de Gerontologia. São Paulo: Atheneu; 2007. p. 807-16.

9. Brito FC, Ramos LR. Serviços de Atenção à Saúde do Idoso. In: Papaléo Netto M, organizador. Tratado de Gerontologia. São Paulo: Atheneu; 2007. p. 671-81.

10. Franchi C. Linguagem: atividade constitutiva. Cadernos de Estudos Linguístico 1992; 22: 9-39.

11. Bakhtin M. Estética da criação verbal. 4. ed. São Paulo: Martins Fontes; 2003.

12. Soares M. Letramento e escolarização. In: Ribeiro VM, organizadora. Letramento no Brasil. São Paulo: Editora Global; 2004. p. 89 - 113.

13. Garcia ALM, Mori-de-Angelis C. Letramento e atuação fonoaudiológica em Unidades Básicas de Saúde. Relatório final de pesquisa apresentada na PUC/SP; 2004.

14. Ribeiro VM. Por mais e melhores leitores: uma introdução. In: organizadora. Letramento no Brasil. São Paulo:Global; 2004. p. 9 - 29.

15. Ribeiro VM, Vóvio, CL, Moura, MP. Letramento no Brasil: alguns resultados do indicador nacional de alfabetismo funcional. Educação e Sociedade 2002; 23(81).

16. Instituto Brasileiro de Geografia e Estatística (IBGE). Censo Demográfico: Brasil; 2000. Rio de Janeiro: IBGE; s.d.

17. Cerri AS, Simões R. Hidroginástica e idosos: por que eles praticam? Movimento 2007; 13 (1), p. 81-92.

18. Fundação Perseu Abramo. idosos no Brasil: vivências desafios e expectativas na $3^{\mathrm{a}}$ idade. São Paulo: Serviço Social do Comércio; 2007.

19. Camarano AA, Beltrão KI, Pascom ARP, Medeiros M, Carneiro IG, Goldani, AM, et al. Como vai o idoso brasileiro? Texto para discussão 1999; 10 (2): 1-63.

20. Silva RCVS. Um estudo de gênero na educação Brasileira. In: Anais da $25^{\text {a }}$ Reunião da Associação Nacional de Pós-graduação e Pesquisa em Educação - ANPED, 2002, Caxambu -MG.1, 48.

21. Souza CHFA. O conhecimento que os professores têm acerca da conceituação de letramento. [dissertação]. Curitiba: Universidade Tuiuti do Paraná; 2008. 
